\title{
Optimal Coordinated Strategy Analysis for the Procurement Logistics of a Steel Group
}

\author{
Lianbo Deng, ${ }^{1}$ Zhuqiang Qiu, ${ }^{2}$ Pengfei Liu, ${ }^{2}$ and Wenzhong Xiao' \\ ${ }^{1}$ School of Traffic and Transportation Engineering, Central South University, Changsha 410075, China \\ ${ }^{2}$ School of Traffic and Transportation Engineering, Changsha University of Science \& Technology, Changsha 410114, China \\ Correspondence should be addressed to Lianbo Deng; lbdeng@csu.edu.cn
}

Received 17 February 2014; Accepted 19 May 2014; Published 4 June 2014

Academic Editor: Andy H. F. Chow

Copyright (c) 2014 Lianbo Deng et al. This is an open access article distributed under the Creative Commons Attribution License, which permits unrestricted use, distribution, and reproduction in any medium, provided the original work is properly cited.

\begin{abstract}
This paper focuses on the optimization of an internal coordinated procurement logistics system in a steel group and the decision on the coordinated procurement strategy by minimizing the logistics costs. Considering the coordinated procurement strategy and the procurement logistics costs, the aim of the optimization model was to maximize the degree of quality satisfaction and to minimize the procurement logistics costs. The model was transformed into a single-objective model and solved using a simulated annealing algorithm. In the algorithm, the supplier of each subsidiary was selected according to the evaluation result for independent procurement. Finally, the effect of different parameters on the coordinated procurement strategy was analysed. The results showed that the coordinated strategy can clearly save procurement costs; that the strategy appears to be more cooperative when the quality requirement is not stricter; and that the coordinated costs have a strong effect on the coordinated procurement strategy.
\end{abstract}

This paper is dedicated to the memory of our best friend, Dr. Zhuqiang Qiu

\section{Introduction}

According to their scope, coordinated procurement logistics can be divided into two forms: internal coordinated procurement and enterprise alliance coordinated procurement. In recent years, through eliminating outdated production capacity and merging and reorganizing between corporations, China's steel industry has achieved the scale production. However, the advantage of large $=$ scale economies has not been brought into full play, and the internal logistics system between subsidiaries lacks integral coordination.

China's steel industry output accounted for 4\% of GDP. The coordinated logistics of this industry shows the following relevant characteristics.

(1) Industry characteristics: the main raw materials for steel enterprises are iron ore, scrap steel, coke, coking coal, and so on. There are obvious homogeneity and substitutability requirements, which provide the operation space for coordinated procurement management.

(2) The competitive environment of the raw material market: the iron ore, coal, and other major upstream industries have a higher industrial concentration than the steel industry, so the whole steel industry faces a relatively unfavourable situation for the negotiation of the prices of raw materials. There is a high correlation between the logistics procurement cost and the degree of synergy of the steel industry.

(3) The resources and industrial layout of China's steel industry: the demand for steel and the distribution of resources in the various regions of China are not balanced, and this leads to a high cost of steel circulation and a low circulation efficiency. Steel production in 2012 was 716.54 million tons, but the total transportation volume of raw materials and steel product was at least 1 billion tons. Collaboration and the integration of procurement logistics are beneficial 
for the steel industry, allowing it to reduce circulation costs significantly and improve market competitiveness.

Increasing the level of coordinated logistics procurement and reducing the production costs of the industry have therefore become a key strategy for the survival and development of China's steel industry.

\section{Literature Review}

Looking at the procurement logistics for a single steel enterprise, Roy and Guin [1] built a conceptual model of justin-time purchasing for a steel company in India. They considered the identification and classification of raw material, supplier availability, and goods consolidation of distribution outlets. For the raw material procurement of a large steel plant, considering three main factors (the selection of raw material model, supplier, and order quantity), Gao and Tang [2] constructed a multiple objective linear programming (MOLP) model for procurement decisions. Hafeez and colleagues [3] considered factors such as human resources, organization, and technology, using the dynamic structure of the integrated system, and described a two-level steel supply chain that achieves a minimized inventory level under the condition of capacity constraints and limits on raw material procurement lead time.

By analysing the procurement policy for iron ore and coke of Japanese steel enterprises in the late twentieth century, Chang [4] argued that changing technology and institutional structure made Japanese procurement decisions more consistent and that this laid the foundations for coordinated procurement between enterprises. Potter et al. [5] made a thorough study of the development process of the British steel supply chain from the traditional mode to the integrated mode in the twentieth century and analysed in detail the impact of the changes on inventory, ordering lead time, and asset utilization. Faes et al. [6] considered that coordinated procurement can lead to better internal exchange of information, an improved market negotiation strategy, significant cost savings, a greater impact on the monopoly market, and a better understanding of the market and cost structure. Akkermans et al. [7] established a theoretical model for coordination and studied the important effects of nontechnological factors on achieving synergy. Essig [8] found that coordinated procurement can reduce transaction costs, allow a lower purchase price to be obtained, and lead to a more efficient use of procurement staff. Bishop [9] showed that coordinated procurement can lead to the integration of the purchase process, better continuity and coordination, and economies of scale. Tella and Virolainen [10] argued that coordinated procurement members wanted to reduce their procurement costs and achieve lower management costs, lower logistics costs, and higher mobility of the inventory. Helo [11] proved that demand coordination was important for improving the capacity of the supply chain.

Türkay et al. [12] established a model and made a quantitative analysis of the cooperation between businesses in the chemical industry. Kraljic's [13] model briefly described the procurement strategy for different materials from the perspective of the profit impact and supply risk involved in procurement. Fu and Piplani [14] established a model that evaluated supplier coordination based on inventory to simulate and assess distributors' performance before and after coordination. The calculations showed that the coordination of suppliers can improve the performance of the whole supply chain. Keskinocak and Savaşaneril [15] used a game theory method to study the coordinated procurement of two competing purchasers. Goyal and Satir [16] used an indirect group strategy to seek a combination of the optimal basic cycle and order frequency to make the total relevant cost a minimum, to achieve optimization of multispecies coordinated procurement. Federgruen and Zheng [17] adopted a direct group strategy and used a heuristic algorithm to optimize the coordinated procurement. Chakravarty and Goyal [18] adopted a dependent and group strategy and used dynamic programming to optimize coordinated procurement. Gurnani [19] studied the design of a supplier quantity discount programme, which is the coordinated procurement of two heterogeneous buyers with different requirement processes and cost parameters. For multiperiod multiproduct batch procurement, Lu et al. [20] established a mixed integer programming model with a constraint on transport capacity and variable transport price, which determined the optimal procurement quantity, by using the Lagrange relaxation theory. Xiang et al. [21] assumed that a group regularly orders and intensively purchases, under the condition of independent demand, from the subsidiaries in a group company and established an optimal order quantity model.

This paper studies the optimization of a group's internal coordinated procurement logistics, when combined with the characteristics $f$ the raw material procurement logistics of steel enterprises. Comparing with other studies, we take the full logistics cost of coordinated procurement strategy and the quality of demand into account in the coordinated procurement problem. On the basis of the optimization model in [22], this paper improves the solution algorithm and analyzes the effect of different parameters on the coordinated procurement strategy.

The rest of the paper is organized as follows. Section 3 presents a brief description of optimization model. In Section 4, we describe our approach in solution algorithm. The base example and its results are shown in Section 5. Results under the conditions of different parameters are analysed in Section 6. Lastly, the conclusions of our findings are summarized in Section 7.

\section{Optimization Model}

This paper studies the CPS of a steel group company that is equipped with a coordinated procurement department and has $m$ subsidiaries (or similar procurement entities). The set of subsidiaries is $I=\{i, i=1, \ldots, m\}$, and the order quantity of raw materials is $Q_{i}$ during a period of length $t$. For simplicity, we assume that all subsidiaries in the coordinated procurement alliance have the same purchase frequency. 
In the supply market, there are $n$ suppliers providing the raw materials; the set of suppliers is $J=\{j, j=1, \ldots, n\}$. We introduce $\gamma(i, j)$, the quality satisfaction degree (QSD) of subsidiary $i$ for the raw material provided by supplier $j$, where $\gamma(i, j) \in[0,1], i=1, \ldots, m, j=1, \ldots, n$. That is,

$$
\gamma(i, j) \geq \gamma_{0}(i), \quad i=1, \ldots, m, j=1, \ldots, n,
$$

where $\gamma_{0}(i)$ is the basic requirement of subsidiary $i$ for raw materials.

The CPS is to procure raw materials for all or some of the subsidiaries by the coordinated procurement department. It can be expressed as $\pi=\left\{\pi_{k}=\left(I_{k} \leftrightarrow j_{k}\right) \mid I_{k} \subset I, j_{k} \in\right.$ $J\}$, where $\pi_{k}$ is a sub-CPS of the CPS, namely, the supply relationship between the set of subsidiaries $I_{k}$ and the supplier $j_{k}$. We introduce

$$
\delta_{k}= \begin{cases}1 & \left|I_{k}\right| \geq 2, \pi_{k} \in \pi \\ 0 & \left|I_{k}\right|=1, \pi_{k} \in \pi\end{cases}
$$

where $\left|I_{k}\right|$ is the number of the subsidiaries in $I_{k}$, for sub-CPS $\pi_{k}$. When $\delta_{k}=1$, the CPS should be adopted; when $\delta_{k}=0$, the independent procurement strategy (IPS) should not be followed.

The sub-CPS should satisfy

$$
\begin{gathered}
I_{k_{1}} \cap I_{k_{2}}=\emptyset \quad \pi_{k_{1}}, \pi_{k_{2}} \in \pi \\
\bigcup_{\pi_{k} \in \pi} I_{k}=I \\
Q\left(\pi_{k}\right)=\bigcup_{i \in I_{k}} Q_{i} \quad \pi_{k} \in \pi,
\end{gathered}
$$

where $Q\left(\pi_{k}\right)$ is the ordering quantity of raw material for the sub-CPS $\pi_{k}$.

Coordinated logistics procurement costs include order preparation costs, storage costs, purchase costs, and transportation costs.

Let $c^{d}$ be the order preparation cost of one batch, $q_{k}$ the order quantity of one batch, and $c^{s}$ the storage cost per unit of raw materials in the coordinated procurement.

The supply price $p_{k}$ and the unit transportation cost $q_{k}$ of a sub-CPS $\pi_{k}$ are, respectively,

$$
\begin{gathered}
p_{k}=p_{j_{k}}-r q_{k} \\
C_{k}^{y}=C_{0}^{y}-C^{y} q_{k},
\end{gathered}
$$

where $p_{j_{k}}$ and $r$, respectively, refer to the initial price and the discount coefficient, $p_{j_{k}}>0$ and $r \geq 0 ; C_{0}^{y}$ and $C^{y}$ refer to the parameters of the transportation cost, $C_{0}^{y}>0$ and $C^{y} \geq 0$.

In contrast to independent procurement strategy (IPS), the additional coordination costs $C_{0}\left(C_{0}>0\right)$ need to be paid in CPS.

Thus, the total logistics costs for sub-CPS $\pi_{k}$ are

$$
\begin{aligned}
C_{k}= & C_{0} \delta_{k}+Q\left(\pi_{k}\right) l_{j_{k}} C_{k}^{y}+Q\left(\pi_{k}\right) p_{k} \\
& +\frac{c^{d} Q\left(\pi_{k}\right)}{q_{k}}+\frac{t}{2} c^{s} q_{k} .
\end{aligned}
$$

Then the optimum order quantity and the optimal cost of $\pi_{k}$ are, respectively,

$$
\begin{aligned}
q_{k}^{*} & =\sqrt{\frac{c^{d} Q\left(\pi_{k}\right)}{\left((t / 2) c^{s}-C^{y} l_{j_{k}} Q\left(\pi_{k}\right)-r Q\left(\pi_{k}\right)\right)}}, \\
C_{k}^{*}= & C_{0} \delta_{k}+Q\left(\pi_{k}\right)\left(C_{0}^{y} l_{j_{k}}+p_{j_{k}}\right) \\
& +2 \sqrt{\frac{t}{2} c^{d} c^{s} Q\left(\pi_{k}\right)-\left(C^{y} l_{j_{k}}+r\right)\left[Q\left(\pi_{k}\right)\right]^{2}} .
\end{aligned}
$$

The above-described situation can, in accordance with Xiao and Qiu [22], be formulated as a multiobjective optimization model as follows:

$$
\begin{array}{ll}
\max & F_{1}=\sum_{\pi_{k} \in \pi} \sum_{i \in \pi_{k}} \gamma(i, j) \\
\max & F_{2}=\frac{1}{\sum_{\pi_{k} \in \pi} C_{k}^{*}}
\end{array}
$$

s.t. Formations (1), (3), (4), and (5).

In this model, the objective function equation (10) is to maximize the QSD for the aggregated demand; the objective function equation (11) is to minimize total procurement cost when all sub-CPSs take the most economic order quantity.

\section{Solution Algorithm}

In order to solve the multiobjective model, we introduce a balancing factor $\alpha(0 \leq \alpha \leq 1)$ of the QSD of total demand, to balance the two objectives. Then the objectives are transformed into the following:

$$
\max F=\alpha \sum_{\pi_{k} \in \pi} \sum_{i \in \pi_{k}} \gamma(i, j)+\frac{(1-\alpha) \beta}{\sum_{\pi_{k} \in \pi} C_{k}^{*}},
$$

where $\beta$ is the cost conversion coefficient of $F_{2}$.

In order to obtain the optimal solution of the global situation, we use an intelligent optimization algorithm, the simulated annealing (SA) algorithm.

The annealing schedule of the SA algorithm refers to a set of process parameters used to control the algorithm, including the generation of a neighbourhood solution, the control of temperature, the number of iterations at each temperature, and the termination rule.

Since sub-CPS $\pi_{k}$ stands for the supplier relationship between the subsidiary sets $I_{k}$ and the supplier $j$, we can adopt a certain rule to select the supplier for each subsidiary; the subsidiaries which select the same supplier and their chosen supplier are composed of the sub-CPS $\pi_{k}$. Automatically the CPS, based on the above initial solution generation method, satisfies the constraints (3) and (4).

According to the objective function, we can select suppliers as follows. For $i \in I$, let its set of alternative suppliers be $J_{i}=\left\{j \mid \gamma(i, j) \geq \gamma_{0}(i)\right\} . \forall j \in J_{i}$, a sub-CPS which consists 
of $i$ and $j$ separately, is defined as $\pi(i, j)=\{(i \leftrightarrow j)\}$. The objective function of this sub-CPS is

$$
F(i, j)=\alpha \sum_{\pi(i, j)} \gamma(i, j)+(\alpha-1) \sum_{\pi(i, j)} \frac{1}{C_{\pi(i, j)}^{*}}
$$

Then, we choose a supplier $j$ from $J_{i}$ according to a selection probability $\varphi(i, j)$, which is

$$
\varphi(i, j)=\frac{F(i, j)}{\sum_{j^{\prime} \in J_{i}} F\left(i, j^{\prime}\right)} .
$$

According to (15) we select the corresponding supplier for each $i \in I$ and merge the sub-CPSs for the same supplier into a new sub-CPS. The definition of $J_{i}$ ensures that all sub-CPSs satisfy the constraint (1) and are feasible.

On the basis of the above analysis, the algorithm is as follows.

Step 0. Initialize. Set the initial temperature to $T_{0}$, the current temperature $T=T_{0}$, the current iterations $h=1$, the optimal solution $\pi_{\mathrm{opt}}=\Phi$, and the objective function $F_{\mathrm{opt}}=\infty$. Use (15) to calculate $\varphi(i, j), \forall i \in I, j \in J$.

Step 1. Randomly generate a sub-CPS $\pi_{i}, \forall i \in I$.

Step 2. Calculate the objective function value $F_{i}$ of each subCPS $\pi_{i}$ using (13).

Step 3. Update the current solution according to the Metropolis criterion: if $F<F_{\text {opt }}$, let $\pi_{\text {opt }}=\pi_{0}$ and $F_{\text {opt }}=F$; otherwise randomly generate a numerical value $\rho$ in $(0,1)$ and if $\rho<\exp \left(-\left(F-F_{\text {opt }}\right) / T_{i}\right)$, then set $\pi_{\text {opt }}=\pi_{0}, F_{\text {opt }}=F$. Otherwise the neighbourhood solution is refused.

Step 4. Judge the number of iterations at the same temperature. The number of iterations at each temperature is restricted by the lower limit of iterations $L$, the accepting rate, $\delta$, of the neighbourhood solution, and the upper limit $H$.

If the iterations satisfy the restrictions, then set $h=h+1$ and move to Step 1; otherwise stop the iterations at the same temperature and move to Step 5.

Step 5. Judge the convergence rule which is a minimum temperature $T_{f}$. If it is not satisfied, then update the current temperature $T=\varepsilon T$, where $\varepsilon$ is a constant close to 1 and move to Step 1; otherwise terminate the algorithm and output the optimal solutions $\pi_{\text {opt }}$ and $F_{\text {opt }}$.

\section{Example Analysis}

5.1. The Base Example. A steel group company has four subsidiary companies: $i_{1}, i_{2}, i_{3}$, and $i_{4}$. A certain raw material is offered by five suppliers: $j_{1}, j_{2}, j_{3}, j_{4}$, and $j_{5}$. The coordinated cost of coordinated procurement $C_{0}=10000$. The transportation cost coefficient $C_{0}^{y}=2, C^{y}=0.001$. The order price discount coefficient $r=0.01$. The preparation cost of each batch order $c^{d}=50$. The unit storage cost for the raw materials $c^{s}=10$.
TABLE 1: Demand of subsidiaries.

\begin{tabular}{lcc}
\hline Subsidiary & $\gamma_{0}(i)$ & Demand \\
\hline$i_{1}$ & 0.60 & 350 \\
$i_{2}$ & 0.65 & 410 \\
$i_{3}$ & 0.62 & 220 \\
$i_{4}$ & 0.70 & 190 \\
\hline
\end{tabular}

TABLE 2: Transportation distance and initial price.

\begin{tabular}{lccccc}
\hline Supplier & $j_{1}$ & $j_{2}$ & $j_{3}$ & $j_{4}$ & $j_{5}$ \\
\hline Transportation distance & 1200 & 1000 & 1500 & 1800 & 1300 \\
Initial price & 35 & 36 & 30 & 32 & 38 \\
\hline
\end{tabular}

TABLE 3: QSD of suppliers.

\begin{tabular}{lccccc}
\hline \multirow{2}{*}{ Subsidiary } & \multicolumn{5}{c}{ Supplier } \\
& $j_{1}$ & $j_{2}$ & $j_{3}$ & $j_{4}$ & $j_{5}$ \\
\hline$i_{1}$ & 0.95 & 0.92 & 0.55 & 0.95 & 0.92 \\
$i_{2}$ & 0.90 & 0.95 & 0.95 & 0.62 & 0.95 \\
$i_{3}$ & 0.50 & 0.85 & 0.87 & 0.60 & 0.85 \\
$i_{4}$ & 0.94 & 0.88 & 0.81 & 0.90 & 0.64 \\
\hline
\end{tabular}

TABLE 4: Sub-CPSs for the base example.

\begin{tabular}{ccccc}
\hline$\pi_{i}$ & $Q\left(\pi_{i}\right)$ & $q_{i}$ & $\bar{\gamma}_{i}$ & $C_{i}^{*}$ \\
\hline$\pi_{1}$ & 190 & 2.75 & 0.940 & $0.53 * 10^{6}$ \\
$\pi_{2}$ & 980 & 10.78 & 0.907 & $2.34 * 10^{6}$ \\
\hline
\end{tabular}

TABLE 5: Sub-IPSs of base example.

\begin{tabular}{ccccc}
\hline$\pi_{i}$ & $Q\left(\pi_{i}\right)$ & $q_{i}$ & $\bar{\gamma}_{i}$ & $C_{i}^{*}$ \\
\hline$\pi_{1}$ & 190 & 2.75 & 0.94 & $0.53 * 10^{6}$ \\
\hline$\pi_{2}$ & 350 & 3.96 & 0.92 & $0.83 * 10^{6}$ \\
$\pi_{3}$ & 220 & 3.10 & 0.87 & $0.73 * 10^{6}$ \\
$\pi_{4}$ & 410 & 4.70 & 0.95 & $1.23 * 10^{6}$ \\
\hline
\end{tabular}

In the period of $t=300$ days, the quantity and quality of the raw materials required are as set out in Table 1.

The transportation distance from the suppliers to the steel group and the initial price are as set out in Table 2.

The QSD of the suppliers' products to meet the needs of subsidiaries are as set out in Table 3.

5.2. The Results. Using the balance factors for the demand satisfaction degree $\alpha=0.7$ and $\beta=10 e^{6}$, we get the CPS $\pi=\left\{\pi_{1}=\left(i_{4} \leftrightarrow j_{1}\right), \pi_{2}=\left(\left\{i_{1}, i_{2}, i_{3}\right\} \leftrightarrow j_{2}\right)\right\}$, and the optimal objective function value is 3.60758. This CPS and its sub-CPSs are seen in Figure 1 and Table 4, respectively.

When we do not adopt the CPS, the optimal independent procurement strategy (IPS) $\pi=\left\{\pi_{1}=\left(i_{4} \leftrightarrow j_{1}\right), \pi_{2}=\right.$ $\left.\left(i_{1} \leftrightarrow j_{2}\right), \pi_{3}=\left(i_{3} \leftrightarrow j_{3}\right), \pi_{4}=\left(i_{2} \leftrightarrow j_{5}\right)\right\}$, and the optimal objective function value $C=3.47748$. This procurement strategy and its subpolicy are shown in Figure 2 and Table 5, respectively. Compared with the IPS, the optimal objective function value of the CPS is $3.74 \%$ higher. On the premise that 


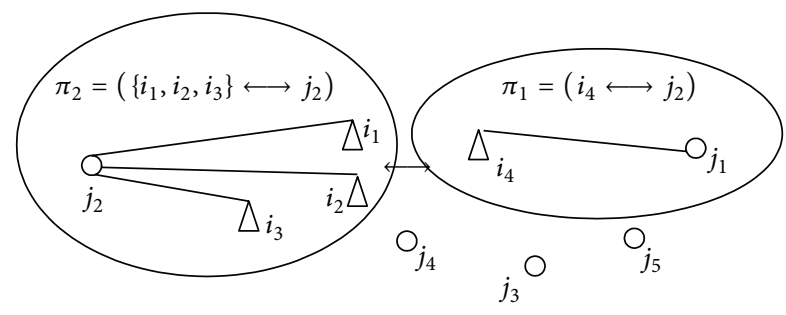

FIGURE 1: CPS of base example.

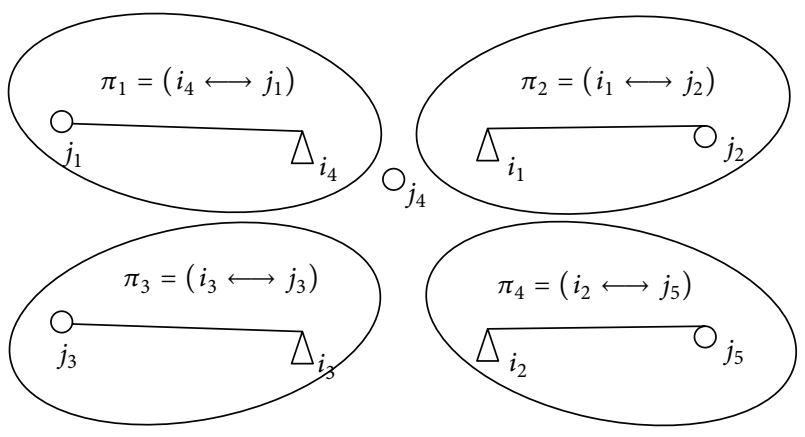

FIGURE 2: IPS of base example.

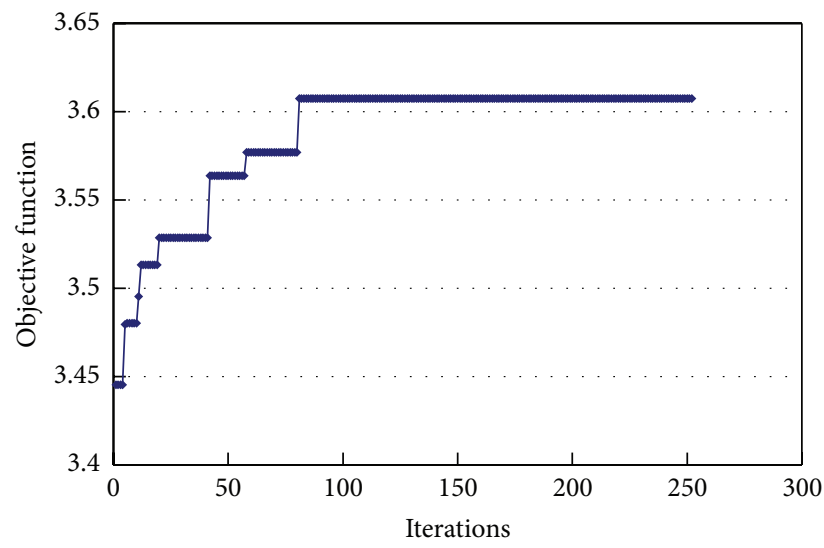

FIgURE 3: Convergence efficiency.

the procurement quality is met, the procurement cost drops remarkably.

5.3. Analysis of Solving Efficiency. During the solving of the base example, when the number of iterations is increased, the optimal solution varies as shown in Figure 3. As we can see, this algorithm has a good effect and can quickly converge to the optimal solution. The convergence speed and solution quality are both very satisfactory.

\section{Results under Other Conditions}

Several factors, including the subsidiaries' requirements for the quality of the raw materials, the supply characteristics of the products in the market, the procurement cost structure, and the balance factor $\alpha$, together have an influence on the

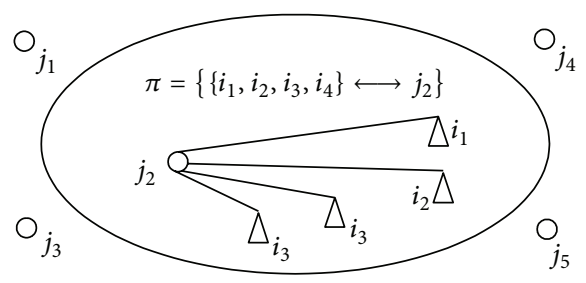

FIGURE 4: CPS under uniform QSD.

TABLE 6

\begin{tabular}{lccccc}
\hline \multirow{2}{*}{ Subsidiary } & \multicolumn{5}{c}{ Supplier } \\
& $j_{1}$ & $j_{2}$ & $j_{3}$ & $j_{4}$ & $j_{5}$ \\
\hline$i_{1}$ & 0.95 & 0.92 & 0.87 & 0.82 & 0.85 \\
$i_{2}$ & 0.95 & 0.92 & 0.87 & 0.82 & 0.85 \\
$i_{3}$ & 0.95 & 0.92 & 0.87 & 0.82 & 0.85 \\
$i_{4}$ & 0.95 & 0.92 & 0.87 & 0.82 & 0.85 \\
\hline
\end{tabular}

TABLE 7: Sub-CPS under uniform QSD.

\begin{tabular}{ccccc}
\hline$\pi_{i}$ & $Q\left(\pi_{i}\right)$ & $q_{i}$ & $\bar{\gamma}_{i}$ & $C_{i}^{*}$ \\
\hline$\pi$ & 1170 & 16.57 & 0.92 & $2.79 * 10^{6}$ \\
\hline
\end{tabular}

TABLE 8: Sub-CPSs under $C_{0}=0$.

\begin{tabular}{ccccc}
\hline$\pi_{i}$ & $Q\left(\pi_{i}\right)$ & $q_{i}$ & $\bar{\gamma}_{i}$ & $C_{i}^{*}$ \\
\hline$\pi_{1}$ & 1170 & 16.57 & 0.90 & $2.78 * 10^{6}$ \\
$\pi_{2}$ & 980 & 10.77 & 0.907 & $2.33 * 10^{6}$ \\
\hline
\end{tabular}

CPS. Here, using the base example, we analyse the results when various factors are changed.

6.1. The Results with a Uniform QSD Condition. In order to find the influence of QSD on the CPS, we take a uniform QSD for each supplier, as set out in Table 6.

We get the optimal CPS $\pi=\left\{\left(\left\{i_{1}, i_{2}, i_{3}, i_{4}\right\} \leftrightarrow j_{2}\right)\right\}$, and the optimal objective function value $C=3.65136$. The results and the specific procurement are shown in Figure 4 and Table 7. Compared with the base example, the optimal objective function value under the uniform QSD condition is increased by $1.21 \%$, and the CPS has an advantage in terms of economies of scale.

6.2. Effects of the Supply Price Discount on the CPS. In this section we analyse the effects of the discount coefficient $r$ on the CPS. The supply price decreases when the order quantity increases, as (6) shows. However, the raw materials for a steel company are both huge in quantity and low in price; the low discount can be provided. When $r=[0,0.25]$, the CPSs are the same; $\pi=\left\{\pi_{1}=\left(i_{4} \leftrightarrow j_{1}\right), \pi_{2}=\left(\left\{i_{1}, i_{2}, i_{3}\right\} \leftrightarrow\right.\right.$ $\left.\left.j_{2}\right)\right\}$. The average QSDs of sub-CPSs $\pi_{1}$ and $\pi_{2}$ are 0.94 and 0.907 , respectively, and the order quantities are $Q\left(\pi_{1}\right)=190$, $Q\left(\pi_{2}\right)=980$, respectively. The objective function values of the CPSs are a little different, with $C=3.60756$ when $r=0$ and $C=3.60761$ when $r=0.25$. However, the discount coefficient $r$ has an obvious effect on the order quantity of the 
TABLE 9: Optimal CPSs under different balance factors.

\begin{tabular}{|c|c|c|c|c|c|c|}
\hline \multirow{2}{*}{$\alpha$} & \multicolumn{6}{|c|}{ CPS } \\
\hline & $\pi$ & $Q_{k}$ & $q_{k}$ & $\bar{\gamma}_{k}$ & $C_{k}\left(10^{6}\right)$ & $F$ \\
\hline 0.0 & $\pi=\left\{\left(\left\{i_{1}, i_{2}, i_{3}, i_{4}\right\} \leftrightarrow j_{2}\right)\right\}$ & 1170 & 16.5725 & 0.9 & 2.78977 & 3.58452 \\
\hline 0.2 & $\pi=\left\{\left(\left\{i_{1}, i_{2}, i_{3}, i_{4}\right\} \leftrightarrow j_{2}\right)\right\}$ & 1170 & 16.5725 & 0.9 & 2.78977 & 3.58762 \\
\hline 0.4 & $\pi=\left\{\left(\left\{i_{1}, i_{2}, i_{3}, i_{4}\right\} \leftrightarrow j_{2}\right)\right\}$ & 1170 & 16.5725 & 0.9 & 2.78977 & 3.59071 \\
\hline 0.6 & $\pi=\left\{\left(\left\{i_{1}, i_{2}, i_{3}, i_{4}\right\} \leftrightarrow j_{2}\right)\right\}$ & 1170 & 16.5725 & 0.9 & 2.78977 & 3.59381 \\
\hline \multirow{2}{*}{0.8} & $\pi_{1}=\left(i_{4} \leftrightarrow j_{1}\right)$ & 190 & 2.75351 & 0.94 & 0.5294 & \multirow{2}{*}{3.62505} \\
\hline & $\pi_{2}=\left(\left\{i_{1}, i_{2}, i_{3}\right\} \leftrightarrow j_{2}\right)$ & 980 & 10.7756 & 0.907 & 2.33982 & \\
\hline \multirow{4}{*}{1.0} & $\pi_{1}=\left(i_{4} \leftrightarrow j_{1}\right)$ & 190 & 2.75351 & 0.94 & 0.52940 & \multirow{4}{*}{3.7100} \\
\hline & $\pi_{2}=\left(i_{3} \leftrightarrow j_{3}\right)$ & 220 & 3.09546 & 0.87 & 0.733107 & \\
\hline & $\pi_{3}=\left(i_{1} \leftrightarrow j_{4}\right)$ & 350 & 4.578 & 0.95 & 1.37965 & \\
\hline & $\pi_{4}=\left(i_{2} \leftrightarrow j_{5}\right)$ & 410 & 4.42068 & 0.95 & 0.976875 & \\
\hline
\end{tabular}

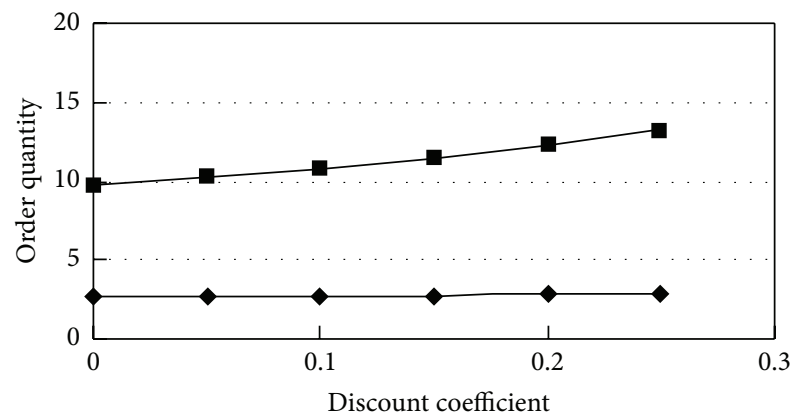

$\neg$ Sub-CPS 1

$\rightarrow$ Sub-CPS 2

FIGURE 5: Effect of $r$ on order quantity.

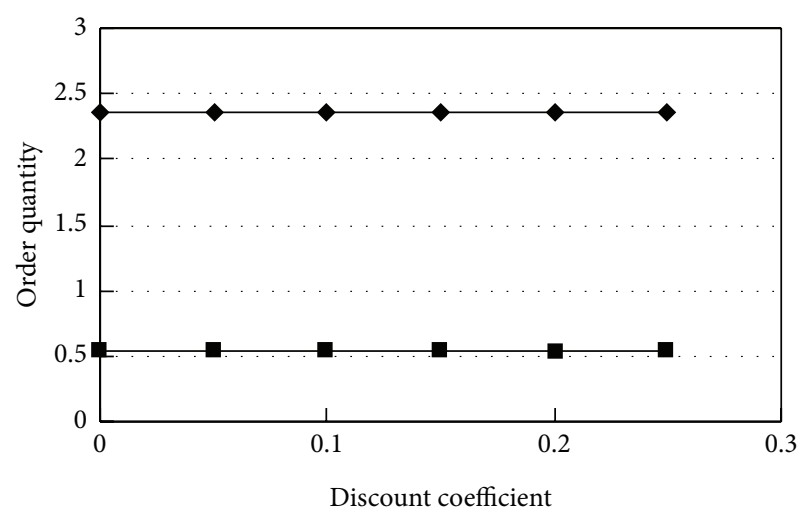

- Sub-CPS 1

Sub-CPS 2

FIGURE 6: Effect of $r$ on procurement cost.

sub-CPSs $\pi_{1}, \pi_{2}$, as Figure 5 shows. In contrast to the order quantity, the difference in the procurement cost of the subCPSs is insignificant, as Figure 6 shows. This is because the price discount for the raw materials is limited. At the same time, the economic order quantity has a regulating function to the effect of price discount.

Thus, within a certain range (e.g., $r \in[0,0.25]$ ), price discount has little effect on the coordinated procurement strategy.

6.3. Impact of the Coordinated Costs on the CPS. The coordinated costs reflect the operation and the coordinated level of the coordinated procurement department in the group company. Compared with a sub-CPS $\pi_{k}=\pi\left(I_{k}, j\right)$, the subIPSs are composed of each of the subsidiaries $i \in I_{k}$ and the supplier $j$; the difference between the logistics costs of the CPS and the IPS is expressed as

$$
\begin{aligned}
\Delta C_{k}^{*}= & C_{0} \delta_{k}+2 \sqrt{\frac{t}{2} c^{d} c^{s} \sum_{i \in I_{k}} Q_{i}-c^{d}\left(C^{y} l_{j_{k}}+r\right)\left[\sum_{i \in I_{k}} Q_{i}\right]^{2}} \\
& -\sum_{i \in I_{k}} 2 \sqrt{\frac{t}{2} c^{d} c^{s} Q_{i}-c^{d}\left(C^{y} l_{j_{k}}+r\right) Q_{i}^{2}} .
\end{aligned}
$$

From (16), we can see that coordinated costs have a direct effect on the CPS and that $\Delta C_{k}^{*} \geq 0$ is a necessary condition for accepting the CPS. $C_{0}=0$ is an ideal situation with the corresponding CPS $\pi=\left\{\pi_{1}=\left(\left\{i_{1}, i_{2}, i_{3}, i_{4}\right\} \leftrightarrow j_{2}\right)\right\}$ and objective function value $C=3.599$, and the sub-CPSs are shown in Table 8. Although the CPS when $C_{0}=0$ is still the same as in the base sample, there are some savings in procurement costs.

However, when $C_{0} \geq 400000$, the optimal CPS tends to disintegrate. Every subsidiary company has its own supplier and the CPS is similar to the one shown in Figure 2.

6.4. Effects of the Balance Factor on the CPS. The balance factor $\alpha$ of the QSD reflects the weighting relationship between the two objective functions and the procurement requirements of the subsidiaries. Under the extreme condition, when $\alpha=0$, the company just needs to consider the procurement costs; when $\alpha=1.0$, the company only needs to 
consider the QSD. With different values of $\alpha$, the CPS varies, as shown in Table 9.

When $\alpha$ is smaller, the purchase logistics of the subsidiaries tend to lead to a higher degree of coordination, and the procurement costs are lower; when $\alpha=0.8$, the CPS shows evidence of disintegration; and when $\alpha=1.0$, every subsidiary purchases its own materials from its own suppliers.

\section{Conclusions}

This paper focused on the optimization of coordinated procurement logistics for a steel group. A simulated annealing algorithm was used to solve this problem. From our analysis of the numerical sample, we can draw the following conclusions.

(1) The CPS can adapt better than the IPS to the internal procurement logistics of the steel company and bring a significant saving in procurement costs.

(2) When the QSD for the quality of the material is not too high or there is no difference between the materials or they are substitutable in the market, the CPS appears to be highly cooperative.

(3) Coordinated costs have a strong effect on the CPS, so a highly advanced coordinated procurement system is the basis for building a significantly efficient coordinated procurement strategy.

\section{Conflict of Interests}

The authors declare that there is no conflict of interests regarding the publication of this paper.

\section{Acknowledgments}

This research is supported by the Science and Technology Research Development Project of the China Railway Corporation (Major Program, 2013X004-A), the Research Fund for the Fok Ying Tong Education Foundation of Hong Kong (Project no. 132017), and the National Natural Science Foundation of China (70901076). This paper is dedicated to the memory of the authors' best friend, Dr. Zhuqiang Qiu.

\section{References}

[1] R. N. Roy and K. K. Guin, "Proposed model of JIT purchasing in an integrated steel plant," International Journal of Production Economics, vol. 59, no. 1, pp. 179-187, 1999.

[2] Z. Gao and L. Tang, "A multi-objective model for purchasing of bulk raw materials of a large-scale integrated steel plant," International Journal of Production Economics, vol. 83, no. 3, pp. 325-334, 2003.

[3] K. Hafeez, M. Griffiths, J. Griffiths, and M. M. Naim, "Systems design of a two-echelon steel industry supply chain," International Journal of Production Economics, vol. 45, no. 1-3, pp. 121130, 1996.

[4] H.-S. Chang, "Coking coal procurement policies of the Japanese steel mills: changes and implications," Resources Policy, vol. 23, no. 3, pp. 125-135, 1997.
[5] A. Potter, R. Mason, M. Naim, and C. Lalwani, "The evolution towards an integrated steel supply chain: a case study from the UK," International Journal of Production Economics, vol. 89, no. 2, pp. 207-216, 2004.

[6] W. Faes, P. Matthyssens, and K. Vandenbempt, "The pursuit of global purchasing synergy," Industrial Marketing Management, vol. 29, no. 6, pp. 539-553, 2000.

[7] H. Akkermans, P. Bogerd, and J. Van Doremalen, "Travail, transparency and trust: a case study of computer-supported collaborative supply chain planning in high-tech electronics," European Journal of Operational Research, vol. 153, no. 2, pp. 445-456, 2004.

[8] M. Essig, "Purchasing consortia as symbiotic relationships: developing the concept of 'consortium sourcing," European Journal of Purchasing and Supply Management, vol. 6, no. 1, pp. $13-22,2000$.

[9] J. E. Bishop, "Consortium purchasing," New Directions For Higher Education, vol. 120, pp. 81-88, 2002.

[10] E. Tella and V.-M. Virolainen, "Motives behind purchasing consortia," International Journal of Production Economics, vol. 93-94, pp. 161-168, 2005.

[11] P. T. Helo, "Dynamic modelling of surge effect and capacity limitation in supply chains," International Journal of Production Research, vol. 38, no. 17, pp. 4521-4533, 2000.

[12] M. Türkay, C. Oruç, K. Fujita, and T. Asakura, "Multi-company collaborative supply chain management with economical and environmental considerations," Computers and Chemical Engineering, vol. 28, no. 6-7, pp. 985-992, 2004.

[13] P. Kraljic, "Purchasing must become supply management," Harvard Business Review, vol. 61, no. 5, pp. 109-117, 1983.

[14] Y. Fu and R. Piplani, "Supply-side collaboration and its value in supply chains," European Journal of Operational Research, vol. 152, no. 1, pp. 281-288, 2004.

[15] P. Keskinocak and S. Savaşaneril, "Collaborative procurement among competing buyers," Naval Research Logistics, vol. 55, no. 6, pp. 516-540, 2008.

[16] S. K. Goyal and A. T. Satir, "Joint replenishment inventory control: deterministic and stochastic models," European Journal of Operational Research, vol. 38, no. 1, pp. 2-13, 1989.

[17] A. Federgruen and Y.-S. Zheng, "The joint replenishment problem with general joint cost structures," Operations Research, vol. 40, no. 2, pp. 384-403, 1992.

[18] A. K. Chakravarty and S. K. Goyal, "Multi-item inventory grouping with dependent set-up cost and group overhead cost," Engineering Costs and Production Economics, vol. 10, no. 1, pp. 13-23, 1986.

[19] H. Gurnani, "A study of quantity discount pricing models with different ordering structures: order coordination, order consolidation, and multi-tier ordering hierarchy," International Journal of Production Economics, vol. 72, no. 3, pp. 203-225, 2001.

[20] K. Lu, C.-H. Yang, and D.-M. Dai, "A Lagrangian-based heuristic algorithm for multi-product capacitated lot sizing with timevarying transportation costs," System Engineering: Theory and Practice, vol. 28, no. 10, pp. 47-52, 2008.

[21] J. Q. Xiang, P. Q. Huang, and J. Li, “Optimal order model under periodic order policy of centralized procurement in enterprise group," Journal of Shang Hai Jiaotong University, vol. 39, no. 3, pp. 474-478, 2005.

[22] W. Z. Xiao and Z. Q. Qiu, "Optimization of coordinated procurement strategy in steel group," Journal of Computer Applications, vol. 7, pp. 1913-1918, 2010. 


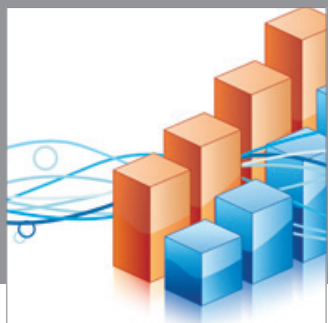

Advances in

Operations Research

mansans

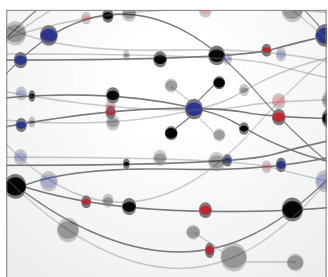

The Scientific World Journal
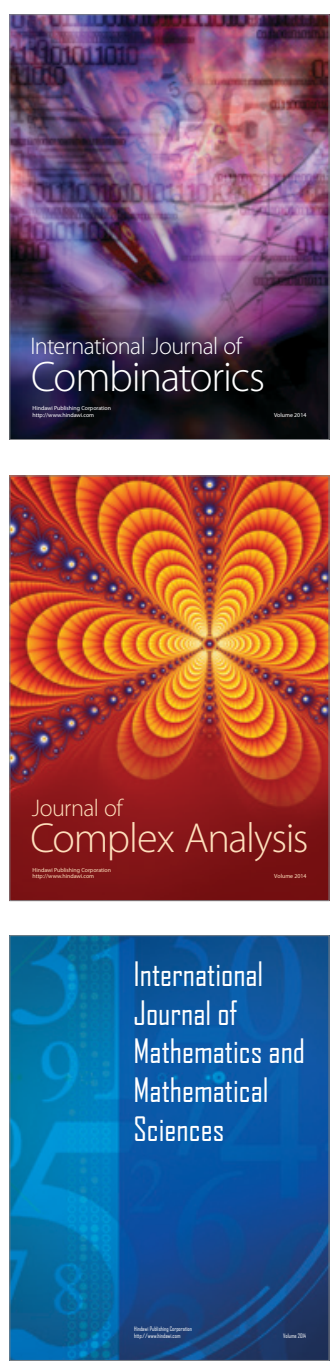
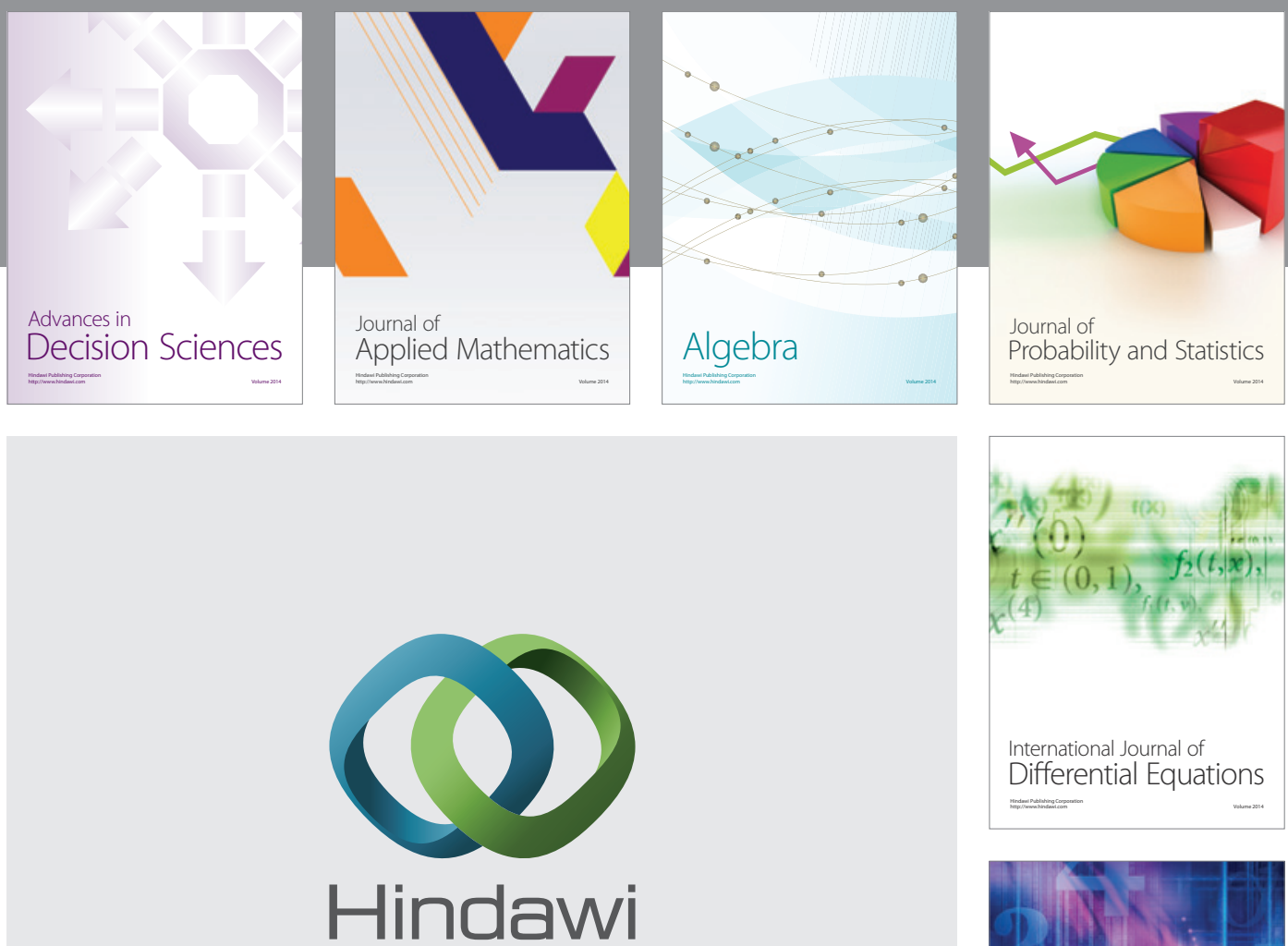

Submit your manuscripts at http://www.hindawi.com
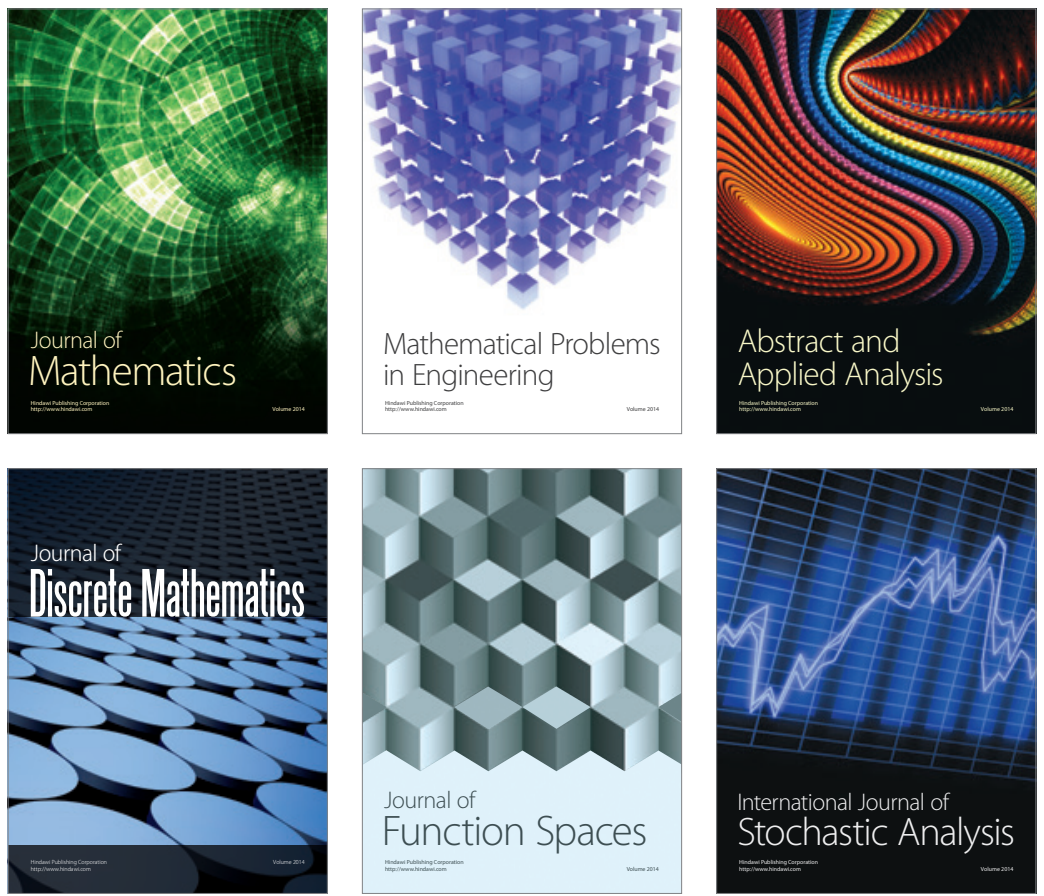

Journal of

Function Spaces

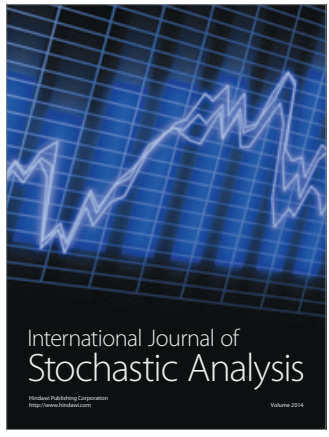

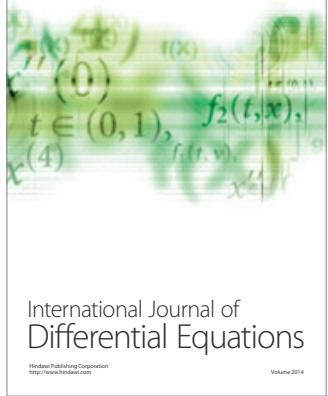
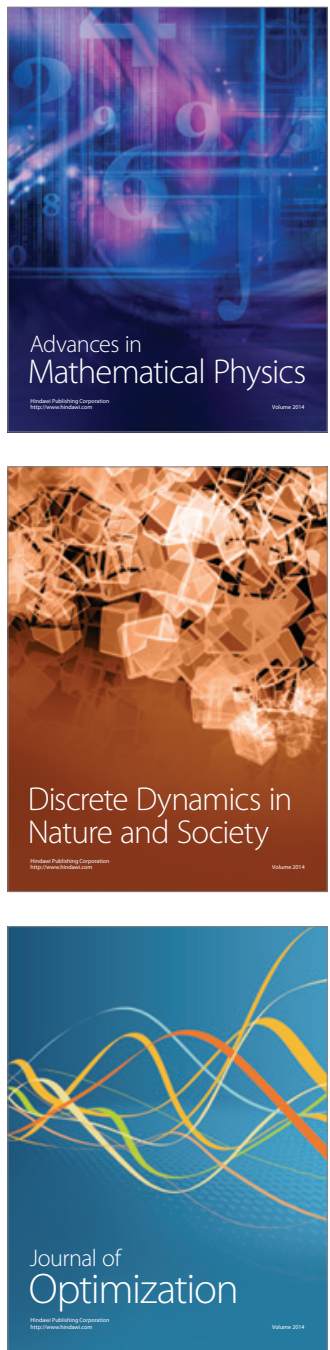